associated with long-term use of venous access devices in patients with cancer. Ann Intern Med 1993;119:1168-1174.

7. Parras F, Ena J, Bouza E, et al. Impact of an educational program for the prevention of colonization of intravascular catheters. Infect Control Hosp Epidemiol 1994;15:239-242.

8. Reagan DR, Doebbeling BN, Pfaller MA, et al. Elimination of coincident Staphylococcus aureus nasal and hand carriage with intranasal application of mupirocin calcium ointment. Ann Intern Med 1991;114:101-106.
9. Davies SJ, Ogg CS, Cameron JS, Poston S, Nobel WC. Staphylococcus nasal carriage, exit-site infection and catheter loss in patients treated with continuous ambulatory peritoneal dialysis (CAPD). Perit Dial Int 1989;9:61-64.

10. Zakrzewska-Bode A, Muytjens HL, Liem KD, HoogkampKorstanje JAA. Mupirocin resistance in coagulase-negative staphylococci after topical prophylaxis for the reduction of colonization of central venous catheters. $J$ Hosp Infect 1995;31:189-194.

\title{
OSHA and JCAHO Form Partnership
}

\section{Gina Pugliese, RN, MS Martin S. Favero, PhD}

OSHA and the JCAHO announced a 3-year partnership to help organizations meet accreditation expectations that promote health and safety for workers. The goals of this partnership are to minimize duplication in compliance activities between the two organizations and to foster improvement in the management of safety and health issues in healthcare organizations.

Cross education and training of JCAHO and OSHA staff already are underway, and 60 JCAHO staff recent- ly participated in a 3-day session to learn how to recognize potential compliance issues related to employee safety and health in healthcare organizations. Plans also are being made for a series of collaborative publications and educational programs.

JCAHO's new Comprehensive Accreditation Manual for Hospitals: The Official Handbook, released in August, details workplace safety and health compliance requirements for healthcare workers and illustrates how compliance with JCAHO standards also satisfies OSHA requirements. JCAHO and OSHA staffs developed the workplace safety and health examples in the manual.

Joseph A. Dear, Assistant Secretary of Labor for Occupational Safety and Health, said, "This is a logical alliance ... . and issues such as infection control, life safety, hazardous materials handling, and performance improvements are our everyday goals. By working together, we can reach these goals more efficiently."

FROM: Joint Commission on Accreditation of Healthcare Organizations. OSHA and Joint Commission collaborate to promote health and safety for health care workers. Chicago, IL: JCAHO Press Release; August 5, 1996. 